\title{
COMPARISON OF PRODUCTIVITY OF STANDARD AND ACCUMULATING FORWARDER GRAPPLE IN THINNING
}

\author{
Guna Petaja, Santa Kaleja, Agris Zimelis, Andis Lazdins \\ Latvian State Forest Research Institute "Silava", Latvia \\ guna.petaja@silava.lv, santa.kaleja@silava.lv, agris.zimelis@silava.lv, andis.lazdins@silava.lv
}

\begin{abstract}
The aim of the study is to evaluate the impact of the accumulating grapple on forwarding productivity in thinning in comparison to the standard grapple and to evaluate potential areas of application of accumulating grapples. Trials were conducted in 3 coniferous stands on nutrient-poor mineral soil with the total area of 15.2 ha. Two work methods are compared in the study - forwarding with a John Deere 1110D ECO III forwarder, equipped either with an accumulating grapple (first method) or a standard grapple (second method). According to the study results the use of the standard grapple results in slight increase of productivity $(2.3 \%$ per load and $1.4 \%$ per $\mathrm{m}^{3}$ of logs). The difference is not significant, however additional trials are recommended to compare both grapples in more fertile forest stands with a larger number of assortments and extracted volumes,

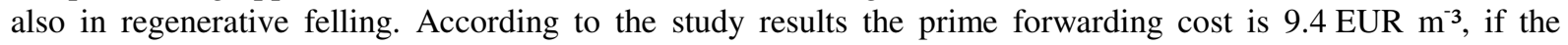
standard grapple is used and $9.5 \mathrm{EUR} \mathrm{m}^{-3}$, if the accumulating grapple is used. The difference is not significant. No significant difference is found between the methods also in terms of damages to the remaining trees.
\end{abstract}

Keywords: forwarding, accumulating grapple, productivity, thinning.

\section{Introduction}

Productivity and cost of forwarding, as well as damages to remaining trees are affected by several factors. Productivity of forwarding is influenced by the types and number of assortments, dimensions of extracted trees, extracted volume, forwarding distance and the machine utilized in the operation. The size and shape of grapple is one of the factors affecting the productivity [1]. Theoretically productivity can be improved by use of grapples, which can load different types of assortments per crane cycle, just like accumulating felling heads can handle several stems simultaneously. According to the results of a study carried out in Canada, productivity of a forwarder ranges from 7.9 to $17.0 \mathrm{~m}^{3}$ per productive work hour [2]. In trials conducted in Sweden in 2014, focusing on productivity and fuel consumption, the standard grapple was equipped with an additional grip. It was found that additional grips do not affect fuel consumption during forwarding. Productivity in this trial increased by 5-8\%, when the accumulating grapple was used. The productivity was mainly influenced by the operator skills and their ability to use the advantages of the accumulating grapple [3].

One of the most important factors influencing productivity of forwarding is the size of the assortment bundle gripped per working cycle. In the study conducted in Sweden the gripped assortment bundle is larger by $15 \%$, when the standard grapple is used. Assuming that the grip can load $0.2 \mathrm{~m}^{3}$ of logs per crane cycle, it is estimated that the accumulating grapple theoretically can load $0.38 \mathrm{~m}^{3}$ of logs per crane cycle. Studies so far approve that use of the accumulating grapple increases productivity of forwarding by $1 \%$, which is considerably less than theoretical improvement of the forwarding performance. The results are explained with differences in the forwarding distance, as well as insufficient experience with the new type of grapple requiring different working methods [3].

The number of assortments depends on the characteristics of the forest stands and bucking instructions, and can vary largely between harvesting sites. According to earlier studies in thinnings and regenerative fellings carried out in Finland, the average number of assortments is 7-10 (45 pulpwood and 3-5 sawlog), but nowadays the numbers might be higher [4]. In Latvia the number of assortments is considerably higher [5;6]. The number of assortments per load influences the forwarding productivity; on the one hand, a bigger number of assortments per load increases the speed of loading, but, on the other hand, it also increases the time consumption during loading out and sorting of logs. In a study carried out in Finland it was found that productivity of forwarding of sawlogs in regenerative felling decreased by $7 \%$, when 2 types of assortments were forwarded in each load instead of 1 type of assortments. In thinning forwarding of 1 type of sawlog assortments decreased the productivity by $20-25 \%$ in comparison to forwarding of mixed loads of 2 types of assortments simultaneously. The productivity of pulpwood forwarding increased by $15-19 \%$ in comparison to mixed loads of pulpwood and sawlogs [7]. 
The aim of the study is to compare the standard grapple and the accumulating grapple in thinning; how the use of accumulating grips and sorting clamps affects productivity and damages to the remaining trees. The grapple with additional grips is manufactured by Swedish companies HSP Gripen [8] and Sit Right AB [9].

\section{Materials and methods}

The study is conducted in 3 Scots pine dominant stands (total area 15.2 ha) on nutrient-poor mineral soils (Cladinoso-callunosa stand type) located in Northern Kurzeme region (Table 1). The trials were carried out from 27.10.2017 till 02.11.2017. The average daily temperature during the trials was 3.1-8.0 ${ }^{\circ} \mathrm{C}$. Shortly before and during the trials there was rainfall $(0.2-5.6 \mathrm{~mm})$ and moderate wind $\left(1.7-7.7 \mathrm{~m} \mathrm{~s}^{-1}\right)$; however the weather conditions did not affect the productivity of forwarding according to the operators' opinion.

Table 1

Site characteristics before thinning

\begin{tabular}{|c|c|c|c|c|c|}
\hline ID & Area, ha & $\begin{array}{c}\text { Growing } \\
\text { stock, } \mathbf{~ m}^{\mathbf{3}} \cdot \mathbf{h a}^{\mathbf{- 1}}\end{array}$ & $\begin{array}{c}\text { Height of } \\
\text { trees, } \mathbf{~ m}\end{array}$ & $\begin{array}{c}\text { Diameter at } \\
\text { breast height, } \mathbf{~ c m}\end{array}$ & $\begin{array}{c}\text { Age in } \\
\text { years }\end{array}$ \\
\hline $703-4133-0$ & 4.5 & 196 & 12 & 11 & 52 \\
\hline $703-4132-0$ & 7.1 & 230 & 13 & 11 & 56 \\
\hline $703-4134-0$ & 3.6 & 230 & 13 & 11 & 58 \\
\hline
\end{tabular}

Forwarding was carried out with a John Deere 1110D ECO III forwarder. Specifications of the forwarder are provided in Table 2.

Parameters of John Deere 1110D ECO III forwarder [10]

\begin{tabular}{|c|c|c|}
\hline Parameter & Measurement unit & Value \\
\hline Unladen weight & $\mathrm{kg}$ & 14700 \\
\hline Maximum engine speed & $\mathrm{rpm}$ & 1900 \\
\hline Engine & $\mathrm{hp}$ & 170 \\
\hline Maximum speed & $\mathrm{km} \mathrm{h}^{-1}$ & 23 \\
\hline Standard speed & $\mathrm{km} \mathrm{h}^{-1}$ & 8 \\
\hline Load space & $\mathrm{m}^{2}$ & 4.3 \\
\hline Length & $\mathrm{m}$ & 9.47 \\
\hline Width & $\mathrm{m}$ & 3.11 \\
\hline Boom length & $\mathrm{m}$ & 10 \\
\hline
\end{tabular}

The forwarder is equipped with a Dala-Gripen DG 29 grapple with the maximum opening of $1560 \mathrm{~mm}$, grip area $-0.29 \mathrm{~m}^{2}$, weight $-240 \mathrm{~kg}$.

Time studies are carried out with a field PC Allegro CX, equipped with the time study program SDI. In addition to time accounting, the number of a strip road, load filling (\%) and assortment type are recorded. A forwarder work cycle is divided into 16 work elements. Description of each element is provided in Table 3.

Table 3

Work operations of forwarding

\begin{tabular}{|c|l|l|}
\hline No & \multicolumn{1}{|c|}{ Operation } & \multicolumn{1}{c|}{ Description } \\
\hline 1 & Drive in & Driving in the felling site \\
\hline 2 & Drive out & Driving out from the felling site \\
\hline 3 & Reach & Accessing logs when loading in \\
\hline 4 & Grip with additional grips & $\begin{array}{l}\text { Gripping logs with the accumulating grapple (first working } \\
\text { method) }\end{array}$ \\
\hline 5 & Reach for the second pile & $\begin{array}{l}\text { Reaching for another bundle of logs after using the } \\
\text { accumulating grip, when loading in (first working method) }\end{array}$ \\
\hline 6 & Grip & Gripping bundle of logs when loading in \\
\hline 7 & Load in & Loading in bundle of logs \\
\hline
\end{tabular}


Table 4 (continued)

\begin{tabular}{|c|l|l|}
\hline No & \multicolumn{1}{|c|}{ Operation } & \multicolumn{1}{c|}{ Description } \\
\hline 8 & Arrange & Arranging logs in bunk \\
\hline 9 & Drive in felling site & Driving in felling site while loading in \\
\hline 10 & $\begin{array}{l}\text { Other operations related to } \\
\text { direct work }\end{array}$ & $\begin{array}{l}\text { Other operations related to work (picking up logs that have } \\
\text { fallen out, levelling out logs etc.) }\end{array}$ \\
\hline 11 & Reach while load out & Accessing logs when loading out \\
\hline 12 & Grip while load out & Gripping bundle of logs when loading out \\
\hline 13 & Load out & Loading out logs from the bunk \\
\hline 14 & $\begin{array}{l}\text { Rearrange assortments in } \\
\text { landing area }\end{array}$ & Sorting logs in the landing area \\
\hline 15 & Drive in landing area & $\begin{array}{l}\text { Driving between piles of assortments in the landing area } \\
\text { while loading out }\end{array}$ \\
\hline 16 & Other & $\begin{array}{l}\text { Other operations, which are not relevant to work (small } \\
\text { repairs and service, checking driving conditions etc.) }\end{array}$ \\
\hline
\end{tabular}

In order to determine the weight of the loads before unloading the CAS multi-platform scales RW-15P are used. Their weighing limit is $15000 \mathrm{~kg}$ per platform, platform dimensions $900 \times 500 \times 39 \mathrm{~mm}$. Each axle is weighed separately.

Two work methods compared during the trials:

- the first work method - forwarding with the John Deere 1110D ECO III forwarder equipped with the accumulating grapple with additional grips mounted on the standard grapple and functioning in semi-automatic regime. Decision on loading of multiple assortments is done by the operator. Load space is split into compartments by 2 pairs of sorters;

- the second work method - forwarding with the John Deere 1110D ECO III forwarder equipped with the standard grapple without additional grips. Load space is not split by sorters.

In both methods operators are instructed to mix assortments in load to avoid unnecessary driving in stand. In total, 6 different assortments were produced in the experimental stands. Maximum length of assortments was $4.5 \mathrm{~m}$.

\section{Results and discussion}

A detailed time study is carried out during forwarding of $424 \mathrm{~m}^{3}$ of logs or 49 loads (average load size $-8.7 \mathrm{~m}^{3}$ or $93 \%$ of the maximum capacity). The average lengths of the strip road and forwarding distance in the trial areas were $640 \mathrm{~m}$ and $775 \mathrm{~m}$, accordingly. In trials the average number of assortments per load is 2.8 , which is relatively a small number in comparison to conventional forwarding conditions in Latvia. Small number of assortments can reduce advantages of the accumulating grapple, which is supposed to be used in areas with high concentration of logs and many different assortments.

On average 61 minutes of productive work time or $68 \mathrm{~min}$ of the total time is consumed per load. Time consumption for each operation is analysed to identify the potential impact of the type of grapple. Productive time consumption per load, using the standard forwarder grapple (second method) and accumulating grapple (first method), is $97 \%$ and $84 \%$ from the total time, accordingly. The reason for the difference is not related to the type of the grapple, therefore, in further calculations these values are replaced by the average value during the studies. Use of the standard grapple resulted in slightly higher productivity ( $2.3 \%$ in comparison to the accumulating grapple).

Forwarding $1 \mathrm{~m}^{3}$ of logs on average took $7.1 \mathrm{~min}$ of productive work time. Use of the standard grapple resulted in slightly higher (by $1.4 \%$ ) productivity values per $\mathrm{m}^{3}$ in comparison to the accumulating grapple (7.0 $\mathrm{min} \mathrm{\textrm {m } ^ { - 3 }}$ and $7.1 \mathrm{~min} \mathrm{~m}^{-3}$ accordingly). There is no statistical difference in productivity between both methods. However, there is statistically significant difference between the operations "reach" $(p=0.0009<0.05)$, "grip" $(p=0.002<0.05)$, "load in" $(p=0.0003<0.05)$, "arrange load" $(p=0.000002<0.05)$, "reach while load out" $(p=0.01<0.05)$ and "load out" $(p=0.02<0.05)$. Operations "reach" and "reach while load out" consume by $19 \%$ less time, if the accumulating grapple is used. Similarly, the operation "grip" takes by $31 \%$ less and "load in" - by 
$21 \%$ less time, comparing with the standard grapple. In case of the standard grapple $28 \%$ less time is spent for the operations "arrange" and "load out". This result approves that the accumulating grapple has advantages during loading, however, these advantages are compensated by additional time consumption for other operations like sorting of logs in the landing site, which can be a result of increased number of assortments per load.

Both operators forwarded similar amount of logs with both work methods. In corridors, where the first operator worked, the forwarding distance is shorter by $10 \%$ in comparison to corridors forwarded by the second operator ( $730 \mathrm{~m}$ and $810 \mathrm{~m}$, accordingly), therefore driving in and out from the stand is not used in comparison of the operators performance.

The second operator spent $72 \%$ less time for the operation "grip with additional grips" $(p=0.0001<0.05)$ in comparison to the first operator. Statistically significant differences are also observed in the operations "reach for the second pile" $(p=0.04<0.05)$, for which the second operator spent $34 \%$ less time, "load in" $(p=0.004<0.05)$, where the first operator has spent $18 \%$ less time than the second, "arrange" $(p=0.005<0.05)$, where the second operator has spent $41 \%$ less time than the first one, "drive in stand" $(p=0.03<0.05)$, where the first operator has spent $25 \%$ less time than the second and "rearrange assortments in landing area" $(p=0.003<0.05)$, where the second operator has spent $69 \%$ less time than the first one. According to these results it is obvious that the second operator avoided the use of the accumulating grip and in both methods tried to use the conventional work approach. Time consumption per $\mathrm{m}^{3}$ differs significantly between the operators for several operations. When the loader is equipped with the standard grapple, the operation "reach" $(p=0.03<0.05)$ takes $20 \%$ less time for the first operator, "load in" $(p=0.03<0.05)$ takes $19 \%$ less time for the first operator, "arrange" $(p=0.02<0.05)$ takes $36 \%$ less time for the second operator, "drive in felling site" $(p=0.0003<0.05)$ takes $49 \%$ less time for the first operator, "load out" $(p=0.03<0.05)$ takes $20 \%$ less time for the first operator and "rearrange assortments in landing area" $(p=0.009<0.05)$ takes $59 \%$ less time for the second operator.

The average productivity, which characterizes the amount $\left(\mathrm{m}^{3}\right)$ of forwarded logs per productive hour, is slightly (by $2 \%$ or $9.7 \mathrm{~m}^{3}$ ) higher for the second operator, however, the difference is not significant. It seems that operators need a longer adaptation period in different work conditions to get used to advantages of the accumulating grapple. It was also obvious that none of the operators adapted to the new equipment during the trials and tried to use the conventional work method, actually, without losing productivity.

The average load size, average forwarding distance and the method specific productivity indicators are considered in the prime cost calculation. The main assumptions applied in cost calculation are provided in Table 4.

Table 5

Average indicators of forwarding with John Deere 1110D ECO III forwarder, used in calculations

\begin{tabular}{|c|c|c|c|c|c|c|}
\hline \multirow{2}{*}{$\begin{array}{c}\text { Type of } \\
\text { grapple }\end{array}$} & $\begin{array}{c}\text { Load } \\
\text { size, } \\
\mathbf{m}^{\mathbf{3}}\end{array}$ & \multicolumn{2}{|c|}{ Productive time per load } & $\begin{array}{c}\text { Average } \\
\text { forwarding } \\
\text { distance, m }\end{array}$ & $\begin{array}{c}\text { Average } \\
\text { driving speed, } \\
\text { m.min }^{-1}\end{array}$ \\
\hline $\begin{array}{c}\text { Accumulating } \\
\text { grapple }\end{array}$ & 8.7 & 37.6 & 9.6 & $85 \%$ & 762 & 51.5 \\
\hline $\begin{array}{c}\text { Standard } \\
\text { grapple }\end{array}$ & 8.6 & 37.8 & 7.6 & $85 \%$ & 762 & 52.0 \\
\hline
\end{tabular}

The prime cost of forwarding logs under bark using the accumulating grapple is $9.5 \mathrm{EUR} \mathrm{m}^{-3}$ and if standard grapple is used -9.4 EUR $\mathrm{m}^{-3}$ (Table 5). In calculations it is assumed that operators are working in 2 shifts and the duration of a shift is 8 hours. The cost of productive hour of a forwarder equipped with the accumulating and the standard grapple is very similar - 52 EUR. Fuel consumption during the trials was $1.81 \cdot \mathrm{m}^{-3}\left(1.3 \mathrm{~kg} \mathrm{CO}_{2} \mathrm{~m}^{-3}\right)$.

Evaluation of mechanical damages of the remaining trees did not demonstrate a significant difference between the both methods; however, the total number of damaged trees was relatively small 
in the study area, and the risk of mechanical damages was not considered as a potential issue in particular stands.

Table 6

Prime cost analysis of forwarding

\begin{tabular}{|c|c|c|}
\hline \multicolumn{1}{|c|}{ Parameter } & $\begin{array}{c}\text { Forwarder with } \\
\text { accumulating grapple }\end{array}$ & $\begin{array}{c}\text { Forwarder with } \\
\text { standard grapple }\end{array}$ \\
\hline Annual cost: & 35244 & 30586 \\
\hline Investment, EUR & 62637 & 62637 \\
\hline Personnel costs, EUR & 59345 & 53109 \\
\hline Operational costs, EUR & 7861 & 7317 \\
\hline Planned income, EUR & 165088 & 153648 \\
\hline Total annual cost, EUR & 6.8 & 6.9 \\
\hline Productivity, $\mathrm{m}^{\mathbf{3}}$ over bark per productive hour $^{\mathbf{3}}$ over bark & 18486 & 18712 \\
\hline Annual production, $\mathrm{m}^{-3}$ over bark & 8.59 & 8.45 \\
\hline Prime cost, EUR $\mathrm{m}^{-3}$ over bark & 9.54 & 9.38 \\
\hline Prime cost, EUR $\mathrm{m}^{-3}$ under bark & & \\
\hline
\end{tabular}

\section{Conclusions}

1. No significant difference in productivity is found between the conventional work method with the standard grapple and the work method considering the use of the accumulating grapple and sorters in the load space. Operations related to loading of assortments take less time in case, when the accumulating grapple is used - "reach" and "reach while load out" require by $19 \%$ less time, "grip" - by $31 \%$ less and "load in" - by $21 \%$ less time, comparing with the use of the standard grapple; however, time savings are compensated by other operations.

2. There is no statistically significant difference of productivity between the operators; however, the working approach of both operators differed considerably - one of them easily adopted to use the accumulating grips and used them often, the other operator tried to use the conventional work method. The most probable reason for the different working approach is the conditions in the study area - relatively small number of assortments ( 2.8 per load) and small concentration of logs around the strip roads; respectively, use of accumulating grips was not necessary in most of the work cycles.

3. Replacement of the standard grapple with the accumulating grapple does not affect the proportion of damaged remaining trees in the stand; however, more fertile conditions and spruce dominant stands should be selected for trials to evaluate the impact on tree damages.

4. Although no statistically significant difference is found between both work methods, the accumulating grapple clearly demonstrated advantages in loading operations. Felling sites with a larger number of assortments and higher concentration of logs, including regenerative fellings, should be selected in further studies to verify these advantages and to adapt to work methods. Longer adaptation period in different work conditions is necessary to get operators used to the new work method.

\section{References}

[1] Sängstuvall L. Estimates of the productivity of logging operations with a focus on forest fuel extraction, Sveriges lantbruksuniversitet, Institutionen för skoglig resurshushållning, Umeå, 2010.

[2] Hiesl P., Benjamin J. Applicability of International Harvesting Equipment Productivity Studies in Maine, USA: A Literature Review, Forests. 4, 2013 pp. 898-921.

[3] Brunberg T., Lundström H., Tidsåtgång och bränsleåtgång vid användning av sortimentsgripen 2014 (Evaluation of assortment grapple 2014 in terms of processing time and fuel consumption), Skogforsk, Uppsala Science Park, 75183 Uppsala, 2016 (In Swedish).

[4] Manner J., Nordfjell T., Lindroos O. Effects of the number of assortments and log concentration on time consumption for forwarding. Silva Fennica, vol. 47, 2013.

[5] Kalēja S., Lazdiņ̌̌ A. Evaluation of impact on assortments' structure on productivity of Timbear harvester in early thinning. Proceedings of the Nordic Baltic Conference OSCAR14, June 25-27, 2014, Knivsta, Sweden, pp. 58-60. 
[6] Lazdiņš A., Kalēja S., Gruduls K., Bārdulis A. Theoretical evaluation of wood for bioenergy resources in pre-commercial thinning in Latvia. Proceedings of Annual 19th International Scientific Conference "Research for Rural Development 2013", May 15-17, 2013, Jelgava, Latvia, pp. 42-49.

[7] Nurminen T., Korpunen H., Uusitalo J. Time Consumption Analysis of the Mechanized Cut-toLength Harvesting System, Silva Fennica, vol. 40, 2006, pp. 335-363.

[8] HSP Gripen of Sweden, HSP Gripen of Sweden - Products, (2018).

[9] SIT RIGHT, DALA-GRIPEN, (2018).

[10] John Deere, Forwarders 1110D Eco III, (2018). 